\title{
Effect of Partial Span Aspiration on the Performance of a Transonic Axial Compressor Rotor: A Numerical Study
}

\author{
Vijaykumar Jain,, Quamber H. Nagpurwala, ${ }^{2}$ and Abdul Nassar \\ ${ }^{1}$ GE Energy, Bangalore 560066, India \\ ${ }^{2}$ Department of Automotive and Aeronautical Engineering, Faculty of Engineering and Technology, \\ M.S. Ramaiah University of Applied Sciences, Bangalore 560058, India \\ ${ }^{3}$ SoftInWay Turbomachinery Solutions Pvt. Ltd., Bangalore 560052, India \\ Correspondence should be addressed to Quamber H. Nagpurwala; qhn1947@gmail.com
}

Received 30 June 2015; Revised 14 September 2015; Accepted 15 September 2015

Academic Editor: Ryoichi Samuel Amano

Copyright (C) 2015 Vijaykumar Jain et al. This is an open access article distributed under the Creative Commons Attribution License, which permits unrestricted use, distribution, and reproduction in any medium, provided the original work is properly cited.

\begin{abstract}
Aspiration in an axial compressor is normally regarded as sucking out the low momentum boundary layer from blade suction surface, thus lowering the chances of flow separation and consequently that of stall under off-design operation. However, the suction mass flow does not take part in useful work and leads to loss of engine power output. This paper deals with a new concept of natural aspiration to energize blade suction surface boundary layer by injecting some fluid from pressure to suction side through a part span slot on the blade. The energized boundary layer has lesser tendency to separate, thus enhancing stall margin. Numerical simulations were carried out to study the effect of aspiration slot location and geometry on the performance and stall margin of a transonic axial compressor rotor. The computational results without aspiration slot were in fair agreement with the published experimental data. The modified rotor, with part span aspiration, showed $\sim 3.2 \%$ improvement in stall margin at design rotational speed. The pressure ratio and efficiency of the aspirated rotor dropped by $\sim 1.42 \%$ and $\sim 2.0 \%$, respectively, whereas the structural analysis did not indicate any adverse effect on the blade stress distribution in the presence of aspiration slot.
\end{abstract}

\section{Introduction}

Axial flow compressors offer high air mass flow rate capacity with small frontal area, which is particularly advantageous for aeroengines [1]. The motivators in the design of present-day gas turbine based aeropropulsion systems are high thrust to weight ratio, wide stable operating range, and high thermal efficiency. The requirement of a compact engine demands compressor modules with less number of stages, which eventually requires high pressure ratio per stage. The choice is to use transonic axial compressor stages owing to their higher pressure ratio capability compared to subsonic stages and higher efficiency compared to fully supersonic stages. However, at high flow Mach numbers, the low loss incidence range of the aerofoil sections becomes narrow, resulting in reduced stall margin. Hence, one of the major concerns of the present-day compressor designer is finding ways and means to enhance the stable operating range of transonic axial compressors. Passive methods are preferred over active methods owing to incorporation of additional gadgets in the latter case which tend to increase the engine weight and reduce reliability.

The main cause of stall inception in axial compressors is the separation of blade suction surface boundary layer at high positive incidence angles. Therefore, a judicious control of the boundary layer flow can result in attached and thinner boundary layers, which can yield higher stage pressure ratio, higher efficiency, and higher stall margin than those achieved by conventional stages. One of the strategies is modifying the blade with an aspiration slot, which will suck the low energy separated fluid from the suction side of the blade, making the downstream boundary layer thinner. Experimental investigation on a 1.6 pressure ratio transonic axial compressor stage, demonstrating the application of boundary layer aspiration on the rotor and stator suction surfaces, has been reported by Schuler et al. [2]. The primary aspiration mass flow rate 
was $0.5 \%$ of the inlet mass flow rate. Additional aspiration totaling $2.8 \%$ was also used at shock impingement location and other locations on the hub and the casing walls. The transonic rotor and the complete stage showed appreciable improvement in efficiency and stall margin. Merchant and Kerrebrock [3] undertook investigation of a 3.4:1 pressure ratio, $457 \mathrm{~m} / \mathrm{sec}$ tip speed, aspirated fan stage for an aircraft engine. The low energy viscous fluid was aspirated from blade and end wall surfaces, enabling very high pressure ratios to be achieved in a single stage with considerable improvement in stall margin. The aspiration flow rate was about $3.5 \%$ of the stage inlet mass flow rate. Aspiration fixed the passage shock position, particularly in the tip region. Kerrebrock [4] carried out investigation on two aspirated compressor stages: (i) a low tip speed, high pressure ratio stage incorporating aspiration in both rotor and stator and (ii) a high tip speed, high pressure ratio fan stage. Major effort was focused on optimizing the blade shapes and minimizing the required blade surface aspiration. Based on the numerical investigation of the flow in tandem compressor cascades, Falla [5] observed that the gap flow from the clearance between the front and the rear blades made it possible to control the separation induced by shock. Therefore, the tandem cascade could sustain larger flow turning and higher pressure ratio without increase in the pressure loss. Merchant [6] demonstrated the impact of boundary layer aspiration through 3D Navier-Stokes computations on two aspirated compressor stages and also on aspirated turbine exit guide vanes. These CFD simulations showed that high loading could be achieved over most of the blade span with a relatively small amount of aspiration. While aspiration was very effective in controlling the blade boundary layer, the role of the end wall could not be neglected in achieving high loading. A three-stage, counterrotating compressor was designed by Freedman [7] to investigate the aspiration technique comprising suction on the surface of the blades and end walls to keep the boundary layer attached under high loading conditions, thus reducing losses. The results reported were encouraging, showing benefits of aspiration or boundary layer suction. Dang et al. [8] designed aspirated compressor blades using 3D inverse method that allowed the blading design with full interaction between the prescribed pressure loading and a specified transpiration scheme. Results showed that an optimum combination of pressure loading, combined with aspiration, could lead to minimization of the amount of suction required for a net performance improvement at design and off-design operations. A low tip speed $(213 \mathrm{~m} / \mathrm{s})$, aspirated fan stage of $1.5: 1$ pressure ratio was experimentally investigated by Kerrebrock [9] to increase the work per blade row through boundary layer control within the flow path. Suction slots were positioned just upstream of both the rotor and the stator tip shrouds for end wall boundary layer removal. The hub end wall boundary layer was also sucked out immediately upstream of the stator. The blade boundary layer flow was removed through slots located on the suction surface of the blade. The aspiration applied at the shock impingement locations prevented separation of the end wall boundary layer along the blade passage. The effectiveness of blade boundary layer suction in a highly loaded compressor cascade was numerically investigated by
Guo et al. [10] with varying suction slot location along the blade chord. The optimal suction location was found to be around $60 \%$ of the blade chord, downstream of the corner separation point. It was concluded that the optimal suction resulted from a balance of external and internal influence. Another numerical study by Liu et al. [11] was focused on removing the end wall corner separation in a compressor cascade. Suction was created with different combinations of slots provided on the blade suction surface and on the end walls. A reduction of $\sim 39 \%$ in total pressure loss coefficient was reported at an incidence angle as high as $+7^{\circ}$.

From the foregoing discussion, it is realized that the research efforts reported so far have focused on creating aspiration by forced suction of blade and end wall boundary layers, including corner separation. The forced boundary layer suction is indeed beneficial in improving the compressor performance in terms of reduced flow separation, increased blade loading, and stable operating range. But there are mechanical complexities involved in manufacturing thin hollow compressor blades that need to be structurally strong too. Further, the forced aspiration requires additional suction equipment, resulting in increased weight and reduced reliability of the total system. The research work reported in this paper deals with the concept of natural aspiration, comprising a partial span slot on the compressor blade connecting the pressure and suction surfaces. The pressure difference between the two blade surfaces acts as the potential force such that the flow from pressure surface crosses over to the suction surface in the form of a jet, energizing the low momentum suction surface boundary layer. The expected result would be reduced tendency of flow separation, increased blade loading, and enhanced stability margin. In the present studies, the natural aspiration technique was implemented on NASA 37 transonic compressor rotor [12]. The compressor was numerically simulated without and with partial span aspirated slots on the rotor blades. The aspiration slot geometry was varied in terms of its chordwise location and width on the two blade surfaces. The simulation results are presented in terms of global compressor performance and detailed flow behavior through the blade passages.

\section{Transonic Axial Compressor}

The NASA 37 transonic axial flow compressor rotor [12] was selected for the present study. The compressor is designed for a total pressure ratio of 2.05 , a corrected mass flow rate of $20.19 \mathrm{~kg} / \mathrm{s}$, and an adiabatic efficiency of $87.7 \%$. The rotor comprises 36 blades having an aspect ratio of 1.19 and hub-tip radius ratio of 0.7 . The design flow coefficient is 0.453 and the rotor tip speed is $454.13 \mathrm{~m} / \mathrm{s}$. More details on the compressor design data can be found in $[12,13]$.

\section{Geometric Model of Baseline Rotor and Flow Domain Discretization}

Present investigations were carried out considering only the rotor of the NASA 37 compressor stage. Geometric model of the rotor, shown in Figure 1, was generated using 


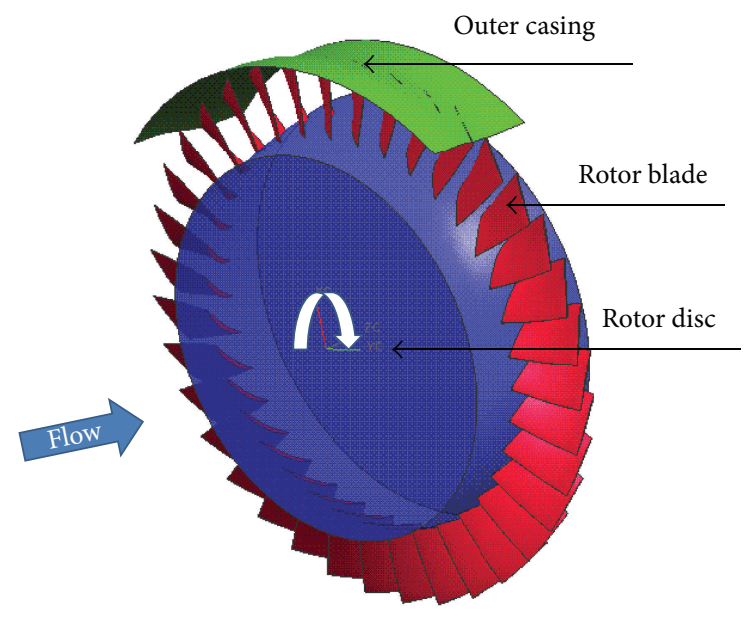

FIgURE 1: CAD model of NASA 37 transonic compressor rotor.

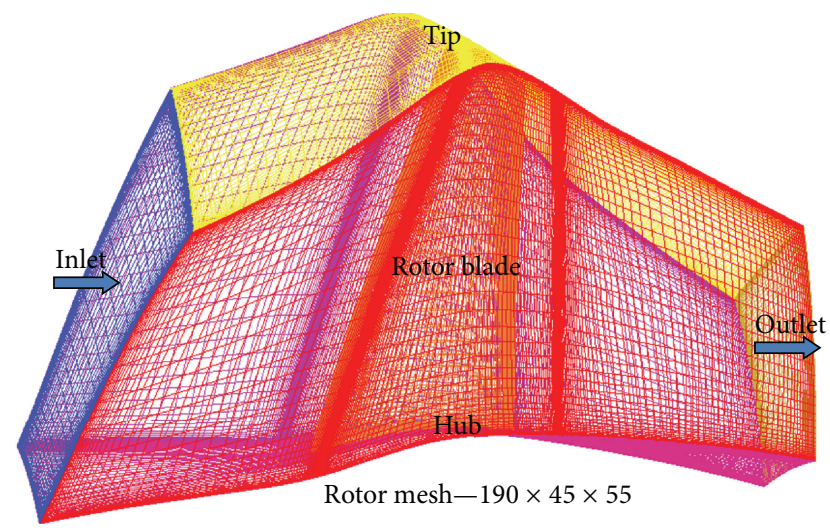

FIGURE 2: Computational grid across one rotor blade passage.

UNIGRAPHICS-NX software. Owing to rotational symmetry, the flow domain comprised a single blade passage, and the same was extracted using UNIGRAPHICS-NX software. The flow domain was extended about two-blade chord upstream and downstream for flow stabilization. The discretization was done using ICEM CFD software with a combination of structured $\mathrm{O}$ and $\mathrm{H}$ grids, as shown in Figure 2. The grid was developed with an acceptable skew angle and determinant of the volumes. The grid density was refined near the hub, casing wall, rotor leading and trailing end, and in the tip clearance region with adequate biasing. The $y^{+}$values were less than 50 at all locations to better resolve the flow behavior near the blade surfaces. A rotor tip clearance of $0.356 \mathrm{~mm}$ was included in the computational model.

\section{Boundary Conditions and Solver Setting}

CFD simulations were carried out with uniform inlet flow conditions. The boundary conditions, specified through ICEM CFD software, are shown in Figure 3. Ambient total pressure and total temperature along with flow direction were specified at domain inlet, and static pressure was specified at domain exit. Rotational periodic boundary conditions

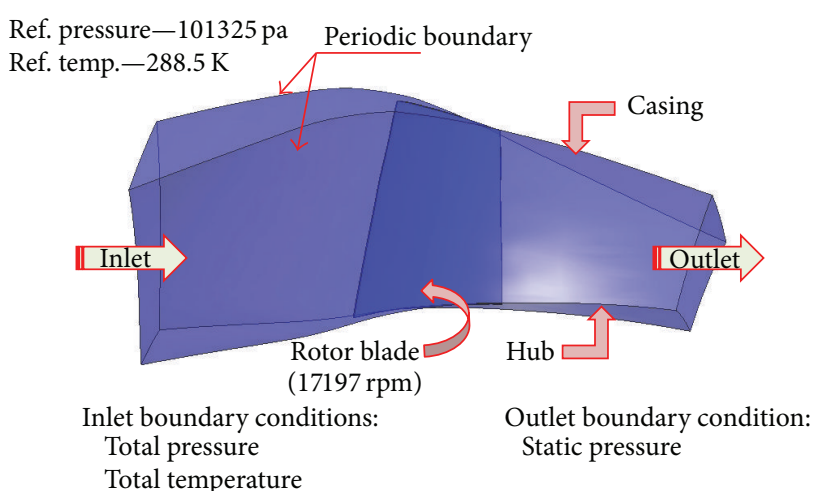

Figure 3: Boundary conditions.

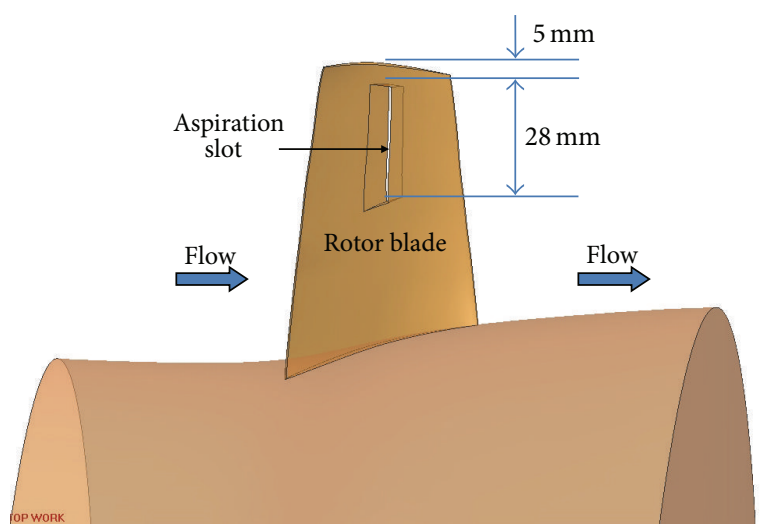

FIGURE 4: 3D CAD model of aspirated rotor blade.

were specified for side boundaries to ensure that all the variables have the same value at both sides of the domain. No-slip boundary condition was applied between the walls and the fluid. The rotational speed was applied to the fluid and the blades were considered to have relative motion with the fluid. The flow was assumed to be axial at the inlet and $z$-axis was taken as the axis of rotation. The numerical simulations were performed using ANSYS CFX software. The $k-\varepsilon$ turbulence model with standard wall functions was used and the compressor stall point was resolved with a back pressure differential of $50 \mathrm{~Pa}$.

\section{Aspirated Rotor Blade}

In order to create natural aspiration across the rotor blade surfaces, a partial-span slot was introduced at a chordwise location, connecting the pressure and the suction surfaces. The length, width, and the skew angle of the aspiration slot were arrived at by examining the flow through the blade passage of the baseline rotor without slot. The length of the slot was kept constant and the other two parameters were varied to generate different variants of the aspirated rotor blade. The slot width and skew angle were varied by varying the start and end points of the slot on the pressure and suction surfaces. A 3D CAD model of the aspirated rotor blade is shown in Figure 4. The flow domains were extracted for all the 
TABLE 1: Geometric details of aspiration slot configurations.

\begin{tabular}{lccc}
\hline & & Configuration details & Slot definition \\
Sl \# & Configuration \# & Location chordwise & $\begin{array}{c}\text { Size }(\mathrm{mm}) \\
\text { Length } \times \text { PS width } \times \text { SS width }\end{array}$ \\
\hline 1 & Baseline R37-0 & NS-SS & Nil \\
2 & AR37-1 & $40 \%-60 \%$ & $28 \times 4 \times 2$ \\
$\mathbf{3}$ & AR37-2 & $\mathbf{4 0} \%-\mathbf{6 0} \%$ & $\mathbf{2 8} \times \mathbf{7} \times \mathbf{4}$ \\
4 & AR37-3 & $50 \%-70 \%$ & $28 \times 4 \times 2$ \\
5 & AR37-4 & $50 \%-70 \%$ & $28 \times 7 \times 4$ \\
6 & AR37-5 & $40 \%-70 \%$ & $28 \times 4 \times 2$ \\
7 & AR37-6 & $40 \%-70 \%$ & $28 \times 7 \times 4$ \\
\hline
\end{tabular}

AR37: Aspirated Rotor 37.

aspirated rotor configurations and the same were exported to ICEM CFD software for discretization. Computational grids were generated using a combination of structured "O" and "H" grids, as was done for the baseline rotor. The grid density was kept high in the aspirated slot region to capture the flow with natural aspiration.

In all, six slot configurations, designated as AR37-1 to AR37-6, were examined. The geometrical details of these are given in Table 1 and a typical aspirated blade and one aerofoil section are shown in Figures 4 and 5, respectively. An example of the dimensional details of AR37-1 (Aspirated Rotor 37 Configuration 1) is given below:
Spanwise length of the slot:

Starting location of slot on pressure surface:

Width of slot on pressure side:

Starting location of slot on suction surface:

Width of slot on suction side:
$28 \mathrm{~mm}$ (fixed for all configurations),

$40 \%$ chord from LE,

$7 \mathrm{~mm}$,

$60 \%$ chord from LE,

$4 \mathrm{~mm}$.
The results of CFD simulations for all the above cases were compared with each other as well as with the baseline rotor without aspiration.

\section{Grid Independence Study}

A grid independence study was carried out on the baseline rotor at $100 \%$ design speed in order to ascertain that the grid size used was appropriate and the results would not vary with any more grid refinement. Four different grid sizes varying from a small number of $\sim 0.36$ million elements (Mesh 1) to a large number of $\sim 1.03$ million elements (Mesh 4 ) were used to check the grid independence. Figure 6 shows the performance of the baseline NASA 37 rotor in terms of variation of total pressure ratio with corrected mass flow rate for the four computational grids. The performance curves for the four grids almost overlap throughout the mass flow range from choke to stall. Hence, a grid size of $\sim 0.578$ million elements (Mesh 2) was selected for the present investigations. For rotor with aspiration slot, the grid size was increased to $\sim 0.65$ million cells with fine grid in the slot region.

\section{Performance of Baseline Compressor without Aspiration}

7.1. Overall Performance. Figure 7 shows the comparison of compressor performance characteristics obtained from present CFD simulations with the experimental data of Reid and Moore [12]. The design point is also marked in the pressure ratio-mass flow rate plot. Whereas the pressure ratio is underpredicted, the adiabatic efficiency is overpredicted compared to the experimental data.

Also, the choke mass flow rate is underpredicted. No specific reason could be assigned to these differences. Broadly, it may perhaps be due to numerical errors and also due to the fact that the stacking axis was modeled as a straight line in the present study because it was not explicitly defined by Reid and Moore [12]. However, a reference to the performance data of NASA 37 compressor stage, obtained through CFD simulations by different researchers and compiled by Denton [14], brings out the fact that there is a large scatter in the results in terms of under- and overpredictions without assigning any specific reasons. It is to be noted that the design point is closer to the results of the present computations.

7.2. Radial Variation of Flow Parameters. The radial variations of total pressure ratio and relative Mach numbers at inlet and exit to the rotor, at an operating point " $\mathrm{A}$ " near design mass flow rate, are shown in Figures 8 and 9. The NASA 37 compressor rotor is reportedly [12] designed for constant pressure ratio along the rotor radius, and the same is manifested in Figure 8. The pressure ratio is underpredicted from hub to midspan, but from midspan to tip, the predicted 


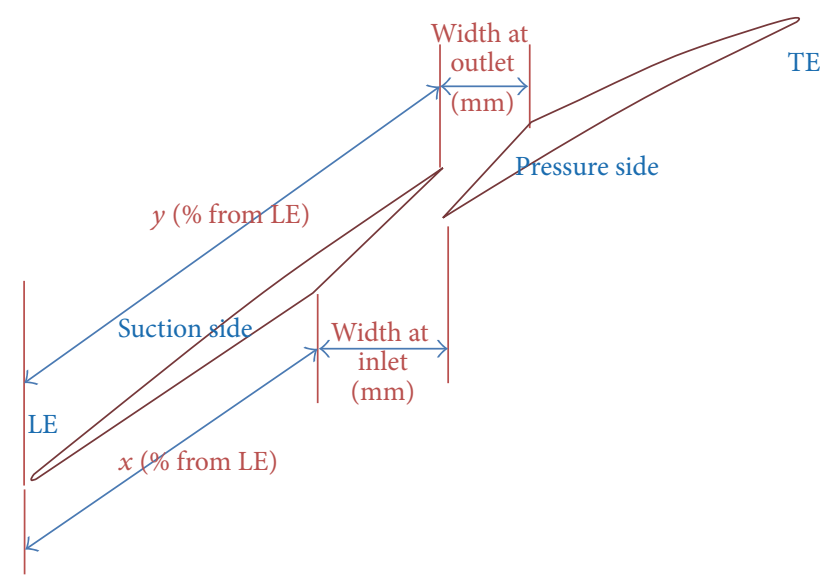

FIGURE 5: A section of rotor blade passing through aspiration slot.

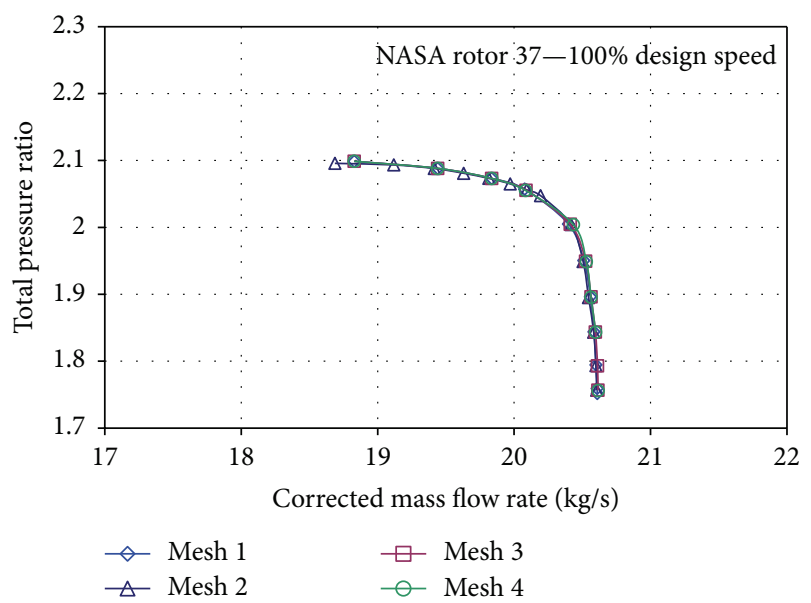

FIGURE 6: Predicted performance characteristics of NASA rotor 37grid independence study.

total pressure ratio agrees quite well with the experimental values. It may be inferred that the underprediction of overall total pressure ratio in Figure 7 is mainly due to the underprediction in the lower half of the blade span.

Referring to Figure 9(a), the predicted inlet relative Mach number agrees well with the experimental data [12] throughout the blade span; the values vary from $\sim 1.2$ at the hub to $\sim 1.5$ at the tip. The relative Mach number at rotor exit (Figure 9(b)) varies from $\sim 0.7$ at the hub to $\sim 0.8$ at the tip. There is underprediction from hub to about $60 \%$ blade span, followed by overprediction up to the blade tip.

7.3. Flow through Rotor Blade Passage. The variations of relative Mach number through rotor blade passage at neardesign mass flow rate (operating point " $\mathrm{A}$ ") and at three radial locations of $95 \%, 72.5 \%$, and $50 \%$ blade span from hub are shown in Figure 10. There is normal shock attached to the leading edge of the blade, occupying more than $50 \%$ of blade span. On one side, the shock impinges on the suction surface of the adjoining blade at almost $50 \%$ chord location and thickens the boundary layer. On the other side, the shock diffuses into the main flow upstream of the leading edge. The shock becomes weaker from tip towards midspan. On the suction surface, initially the flow decelerates across the shock, followed by gradual acceleration until the flow again encounters the shock impinging from the adjoining blade. There is sudden flow deceleration across the passage shock followed by gradual flow deceleration till the trailing end. Similar observations on the same rotor have been reported by Suder [15].

Figure 11 shows the variation of relative Mach number through the blade passage at near-stall operating condition (operating point "B"). Owing to the reduced mass flow rate at positive incidence angle, the blade loading increases. The shock moves upstream and detaches from the leading edge. At 95\% span, there is indication of large-scale flow separation on the suction surface, and the low energy fluid, under the influence of increased tip leakage flow, occupies a position at the mid blade passage. At $72.5 \%$ and $50 \%$ blade span, the boundary layer further thickens owing to increased blade loading and the shock impinging on the suction surface. As the shock has moved upstream, so is the impingement location on the blade and the point of flow separation. At 95\% span, the incoming flow initially decelerates across the detached shock, followed by strong acceleration near the leading end.

Figure 12 shows chordwise distribution of isentropic relative Mach number on the blade surface at $72.5 \%$ blade span at operating points corresponding to design and near-stall mass flow rates. The flow behavior on the suction surface corresponds to the above discussion with reference to Figures 10 and 11. As the operating point moves from design mass flow rate " $A$ " to stall mass flow rate " $B$," the location of peak Mach number on the suction surface moves upstream from $50 \%$ axial chord to $\sim 30 \%$ axial chord. The peak suction surface Mach number is higher at the stall point " $B$ " than at the design point "A." However, the suction surface Mach number just downstream of the shock is apparently not affected with a change in operating point. Further downstream up to the trailing end, the flow on the suction surface decelerates faster at operating point " $\mathrm{A}$ " than at point " $\mathrm{B}$ " owing to the shift in shock location. However, the pressure surface Mach number is not much affected by the change in operating point except near the leading end. The blade loading in terms of static pressure difference across pressure and suction surfaces reduces in the aft part of the blade and increases in the forward part up to $20 \%$ axial blade chord as the operating point shifts from design mass flow rate "A" to stall mass flow rate "B."

\section{Performance of Compressor with Aspiration}

As mentioned earlier, the present studies were focused on the effectiveness of natural aspiration across the blade surfaces through a partial span slot in the upper part of the span. The location of the slot opening was chosen based on the pressure differential across the blade surfaces and also the shock impingement location. The slot was configured to be inclined at a streamwise angle to the suction surface so that the ensuing jet would not lift off the surface. The slot was also 


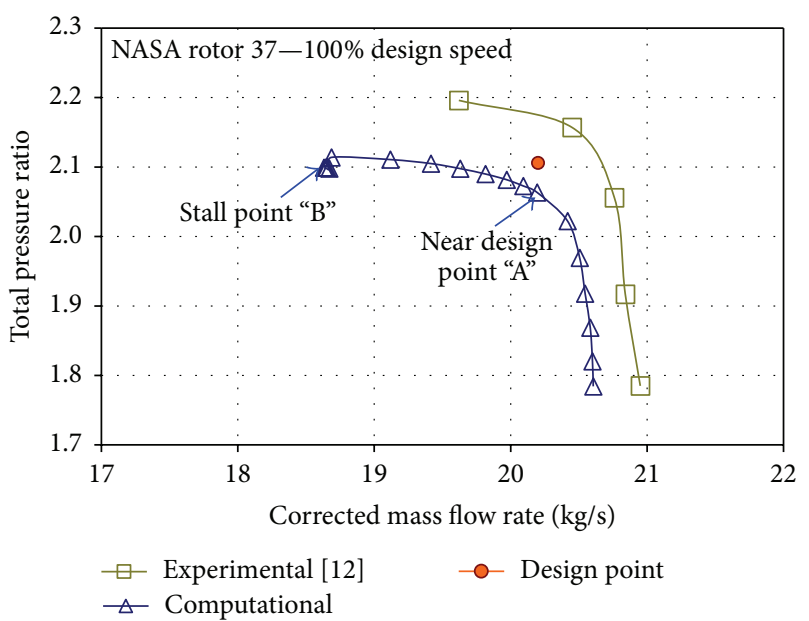

(a)

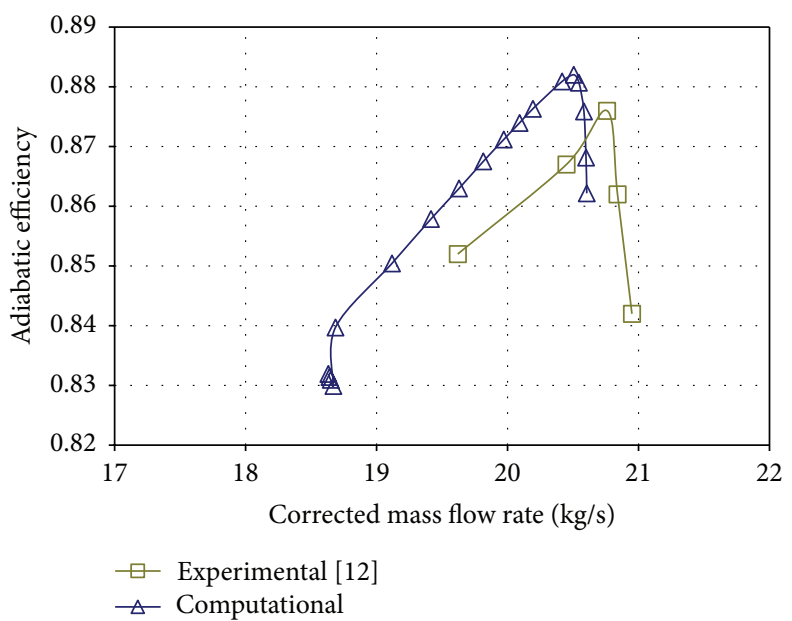

(b)

Figure 7: Predicted performance characteristics of baseline compressor at $100 \%$ design rotational speed and comparison with experimental data of [12].

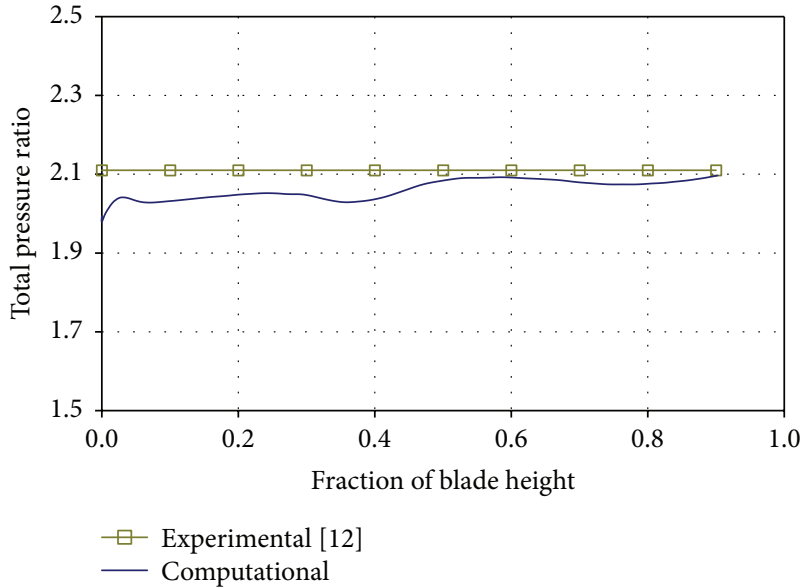

FIGURE 8: Radial variation of total pressure ratio across the rotor at $100 \%$ design rotational speed and comparison with experimental data of [12].

tapered with reduction in flow area from pressure surface to suction surface, so that it would act as a nozzle and accelerate the aspiration flow in the form of a high velocity jet. The net effect would be accelerating the suction surface boundary layer downstream of the shock impingement point, so that the low momentum boundary layer would energize and become less prone to separation. This would then result in lowering the stall mass flow rate and consequent enhancement of stall margin.

The geometric parameters of the aspiration slot that influence its effectiveness are as follows:

(i) chordwise location on pressure surface,

(ii) chordwise location on suction surface,

(iii) width on pressure surface,

(iv) width on suction surface, (v) spanwise length,

(vi) spanwise location.

A judicious choice of these parameters would depend upon the flow characteristic through the blade passage. In order to narrow down the scope of present investigations, only two geometric parameters, namely, widths of the slot on pressure and suction surfaces and chordwise location of the slot, were considered in different combinations. The spanwise

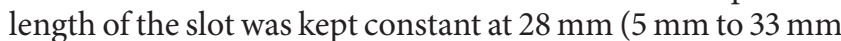
from blade tip). Table 1 lists the dimensional details of six configurations of aspiration slots, designated as AR37-1 to AR37-6, considered in the present studies.

8.1. Overall Performance. The overall performance of the compressor, in terms of variation of total pressure ratio and adiabatic efficiency with mass flow rate, with different aspiration slot configurations is compared in Figure 13. Table 2 lists the changes in stall margin, peak pressure ratio, and peak adiabatic efficiency for rotors with different aspiration slot geometries. Both pressure ratio and adiabatic efficiency are reduced with aspiration for all slot configurations compared to the compressor without aspirated blades. While the peak pressure ratio drops from 2.12 to 2.06 , the peak adiabatic efficiency is reduced from 0.881 to 0.863 , except for the aspiration slot configuration AR37-2, which shows a bit larger drop in both peak total pressure ratio and peak efficiency. However, all the aspirated slot configurations show a reduction in stall mass flow rate compared to the baseline rotor. The maximum benefit is found for AR37-2, which gives a stall point mass flow rate of $18.04 \mathrm{~kg} / \mathrm{sec}$ compared to the baseline stall point mass flow rate of $18.63 \mathrm{~kg} / \mathrm{sec}$. The reduction in the stall point mass flow rate is $0.59 \mathrm{~kg} / \mathrm{sec}$, which yields $\sim 3.2 \%$ increase in the stall margin. Similarly all other aspirated configurations show some gain in stall margin, but these are lower than that of AR37-2. 


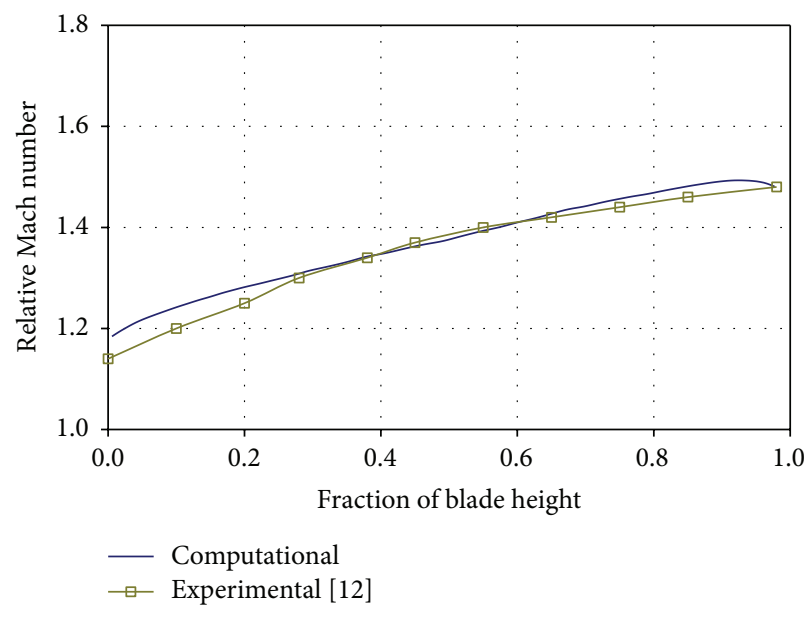

(a) Inlet to rotor

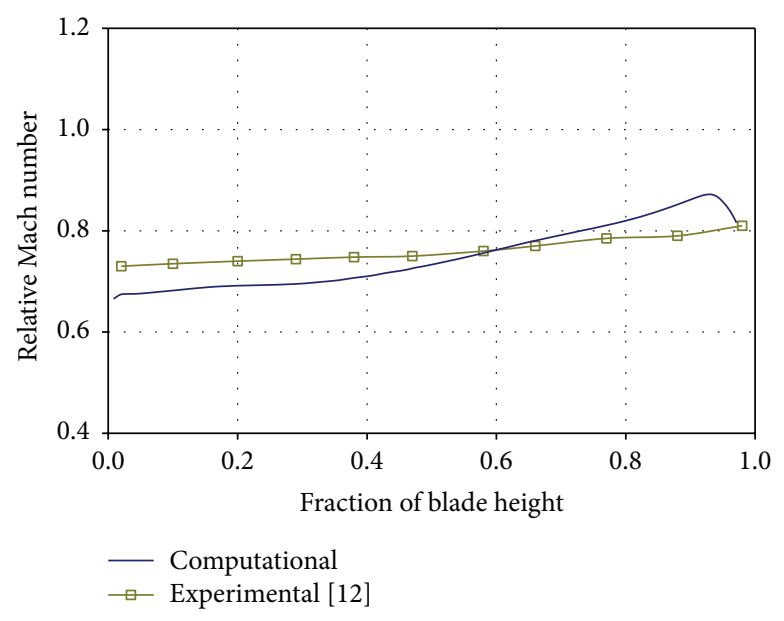

(b) Exit to rotor

FIGURE 9: Radial variation of relative Mach number at inlet and exit to the baseline rotor at 100\% design rotational speed and comparison with experimental data of [12].

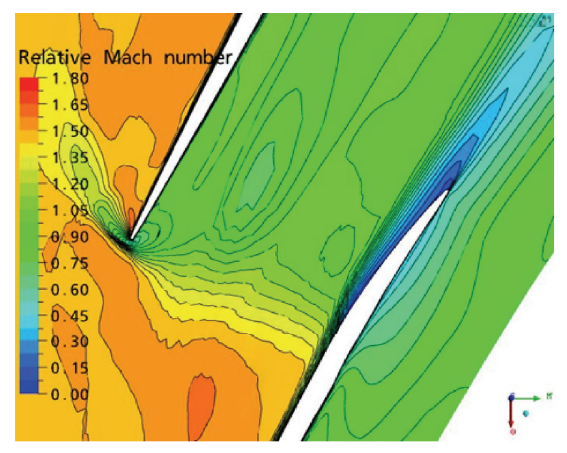

(a) $95 \%$ span from hub

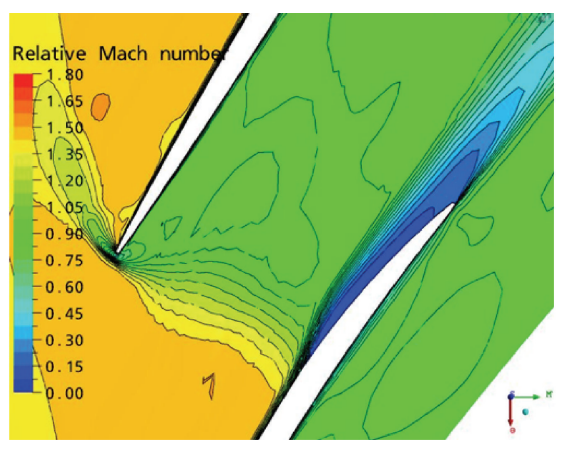

(b) $72.5 \%$ span from hub

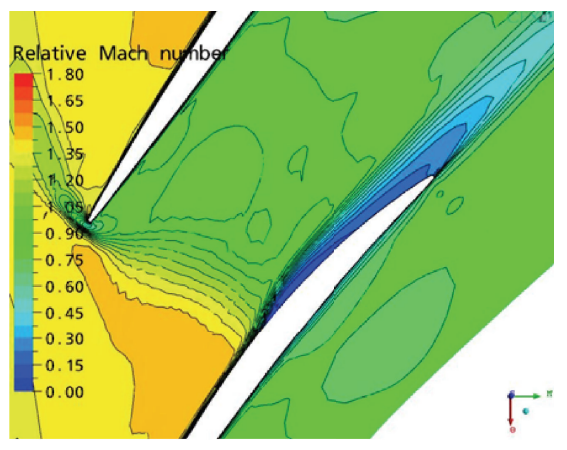

(c) $50 \%$ span from hub

Figure 10: Relative Mach number distribution in the blade passage of baseline rotor at three spanwise locations from hub (100\% design rotational speed, near-design mass flow rate).

The reduction in pressure ratio in the presence of the aspiration slots is obvious as the swept area is decreased. There is reduction of $6.9 \%$ of swept area in AR37-2. Similarly all other slot configurations result in around 3.2\% to 6.9\% reduction in swept area compared to the baseline blade. The aspiration slot, having a width of $7 \mathrm{~mm}$ on pressure surface, has a reduction of $6.9 \%$ in swept area and the slot having a width of $4 \mathrm{~mm}$ on pressure surface has a reduction of $3.2 \%$ in swept area. The lowering of efficiency is also due to reduced swept area, which causes lower work to be done by the rotor blade on the fluid, or, in other words, the energy imparted by the rotor blade to the fluid is less compared to the baseline rotor blade. But the energy required by the rotor may remain high in order to push the flow across the aspiration slot. The above results show that the slot location and slot width have an impact on the stall point mass flow rate.

8.1.1. Effect of Aspiration Slot Location. From the foregoing discussion, it is logical to presume that the location of the aspiration slot opening on the blade suction surface should play an important role. The passage shock impinging on the suction surface enhances boundary layer separation and the aspirated fluid tends to energize the low momentum surface fluid, thus delaying separation. Referring to Tables 1 and 2 , the aspiration slot geometries open at $60 \%$ or $70 \%$ chord on the blade suction surface. Some observations related to these two cases are given below.

Case 1. Aspiration slot exiting on suction side at $60 \%$ chord: here, the aspiration helps to suppress the boundary layer separation by energizing the flow on the suction side. Further, the aspiration interacts with the passage shock. As a result, the shock moves upstream and its interaction with the boundary layer is reduced. The overall effect is reducing the extent of low velocity zone in the blade passage, hence improving the stall margin.

Case 2. Aspiration slot exiting on suction side at $70 \%$ chord: here, the aspiration helps only in suppressing the boundary layer separation by energizing the flow on the suction side. As a result the stall margin is improved but not to the extent seen in Case 1. 


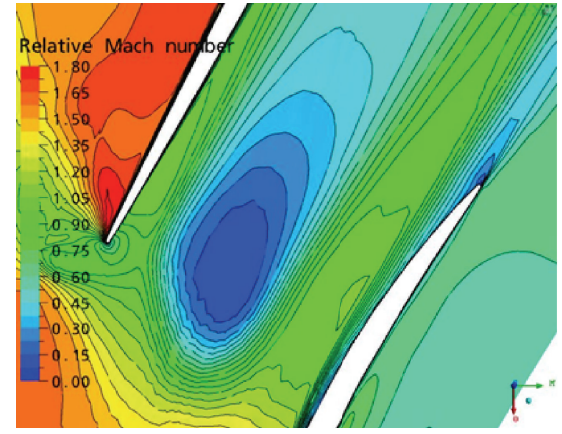

(a) $95 \%$ span from hub

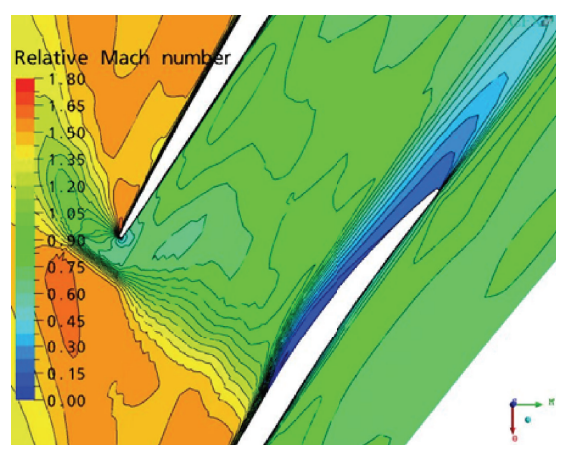

(b) $72.5 \%$ span from hub

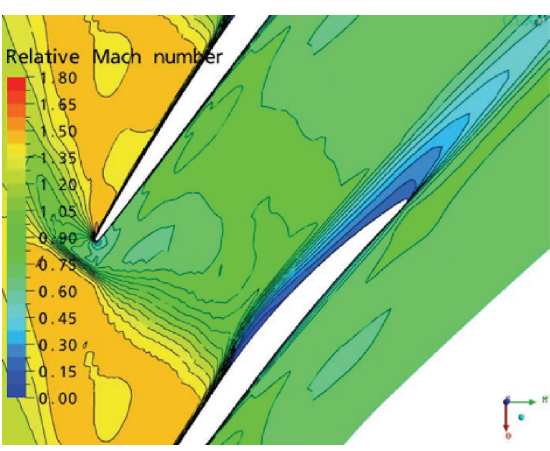

(c) $50 \%$ span from hub

FIGURE 11: Relative Mach number distribution in the blade passage of baseline rotor at three spanwise locations from hub (100\% design rotational speed, near-stall mass flow rate).

TABLE 2: Performance of compressor rotor for different aspirated slot configurations (100\% design rotor speed).

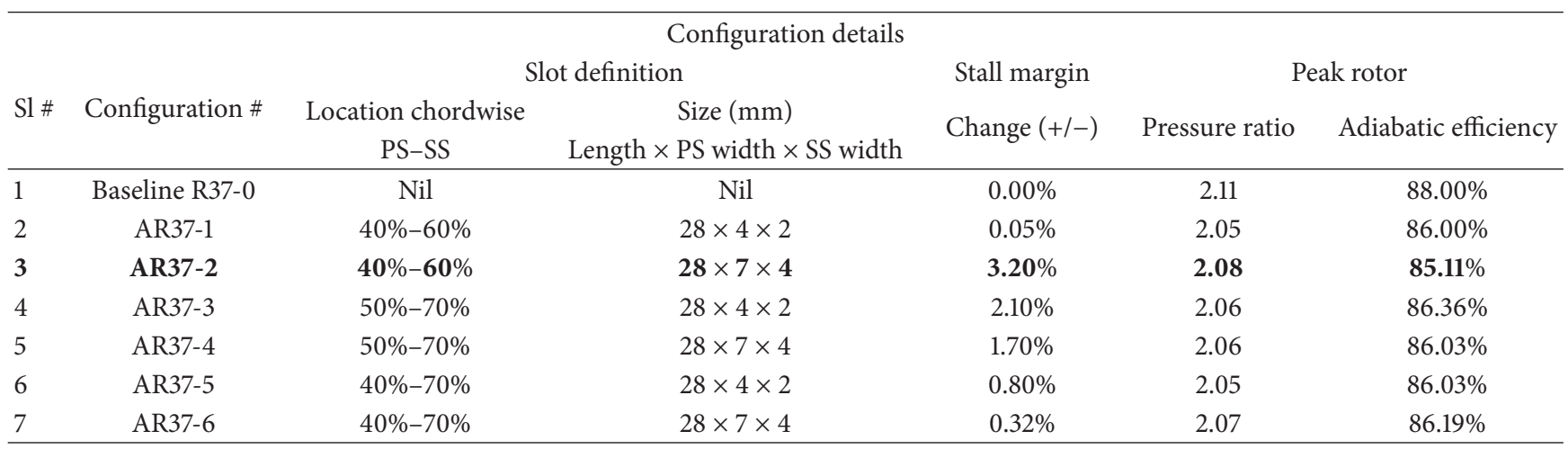

AR37: Aspirated Rotor 37.

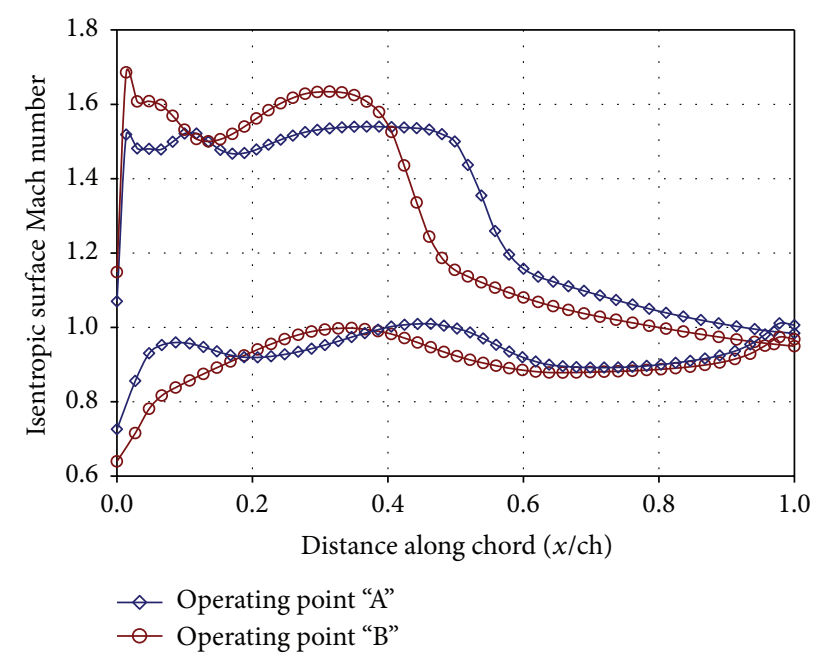

FIGURE 12: Isentropic surface Mach number variation on the baseline rotor at a radial location $72.5 \%$ span from hub (100\% design rotational speed).

8.1.2. Effects of Aspiration Slot Width. It is also logical to assume that the effectiveness of aspiration is controlled by the momentum of the aspirated fluid crossing from blade pressure surface to suction surface. For a given pressure differential across the blade surfaces, the momentum is controlled by the aspiration mass flow, which, in turn, depends on the slot opening. Referring to Tables 1 and 2, the two cases of slot opening, corresponding to $7 \mathrm{~mm}$ and $4 \mathrm{~mm}$, are discussed below.

Case $1.7 \mathrm{~mm}$ width of aspiration slot on pressure surface: here, the aspiration mass flow is more and hence it helps to improve the stall margin as in AR37-2, but it is not effective in the other two cases. This is because, in AR37-2, the flow exits at $60 \%$ chord location on the suction surface just after the shock, where more flow momentum is required to energize the boundary layer.

Case 2. $4 \mathrm{~mm}$ width of the aspiration slot at inlet on pressure surface: here, the aspiration mass flow is less and it has lesser capacity to energize the flow at the shock impingement location. But it helps at other locations to improve the flow behavior to some extent.

8.2. Radial Variation of Flow Parameters: Aspirated Rotors. The radial variation of total pressure ratio for the six aspirated rotor configurations is shown in Figure 14 at mass flow rates corresponding to design point and near-stall point. At design mass flow rate, the total pressure ratio is lower at the hub and increases towards the tip. At near-stall mass flow rate, the total 


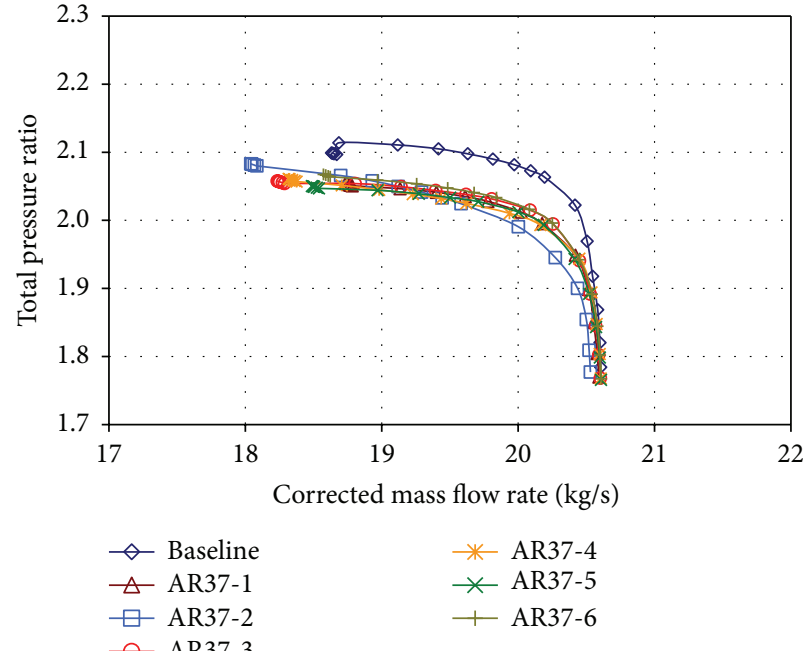

(a)

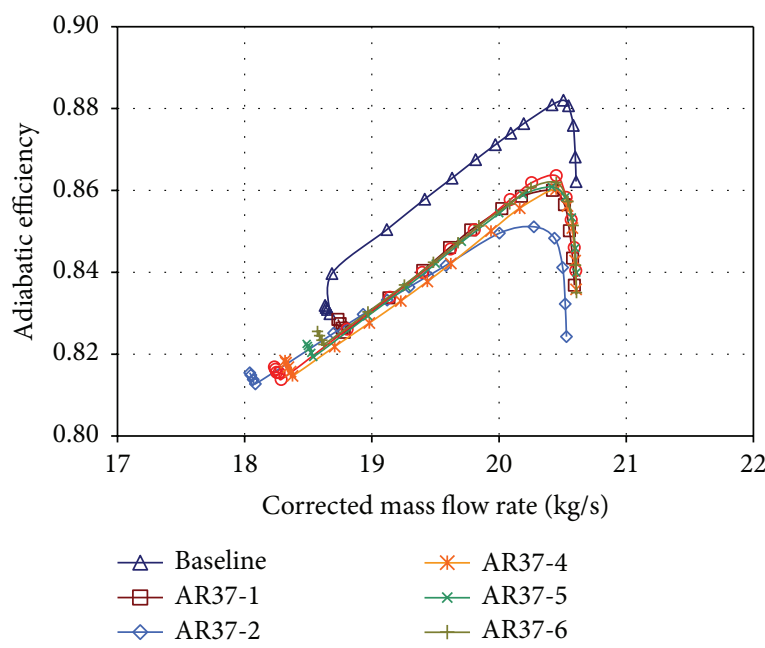

(b)

FIGURE 13: Predicted performance characteristics of compressor rotor for different aspiration slot configurations (100\% design rotational speed).

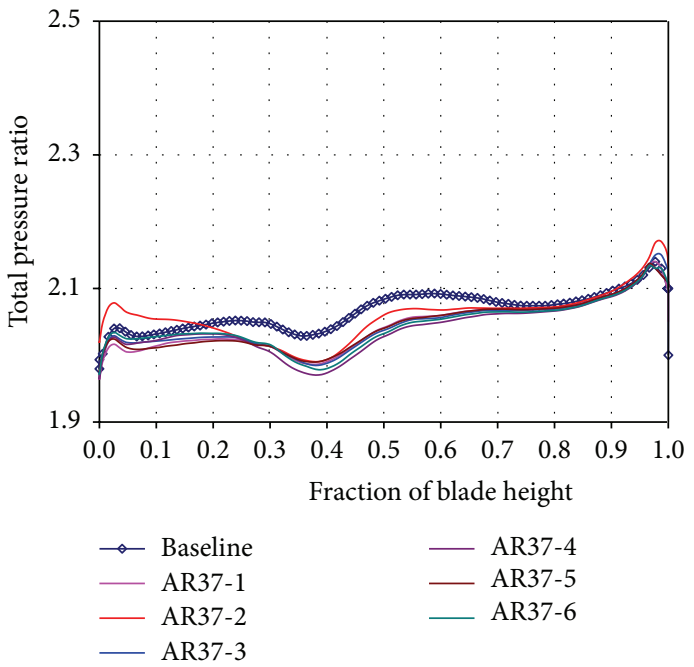

(a) Design mass flow rate

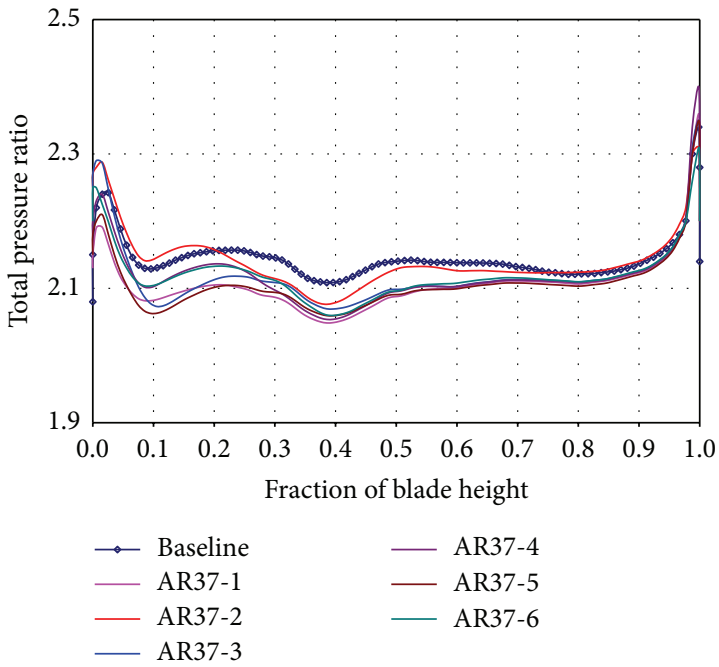

(b) Near-stall mass flow rate

FIGURE 14: Radial variation of total pressure ratio across the rotor for different aspiration slot configurations (100\% design rotational speed).

pressure ratio becomes higher throughout the blade span. The increase is quite substantial in the tip region. Beyond $75 \%$ span, all the aspiration slot configurations produce the same pressure ratio across the rotor at both design and nearstall mass flow rates. However, below $75 \%$ span, the total pressure ratio shows some variations with different aspiration slot configurations.

Figure 15 shows the radial variation of relative Mach number at the exit of the baseline and aspirated rotors for both design and near-stall operating conditions. There is no appreciable effect of aspiration slot configuration on the pitch-wise mass-average exit relative Mach number. The values are lower at near-stall operating point owing to lower mass flow rate than at the design point. Also, the variation of
Mach number from hub to tip is steeper at design mass flow rate than at near-stall flow rate.

8.3. Flow through Rotor Blade Passage. To understand the effectiveness of natural aspiration in improving the compressor stall margin, the flow behavior through the blade passages is studied for the configuration AR37-2 at near-stall operating point. Figure 16 shows the variations of relative Mach number through rotor blade passage at three radial locations of $95 \%, 72.5 \%$, and $50 \%$ blade span from hub. Comparing the Mach number distribution in Figure 16(a), it is noted that the separated flow region at $95 \%$ span is greatly reduced in the presence of natural aspiration. The inlet shock is smeared and detached from blade leading edge. 


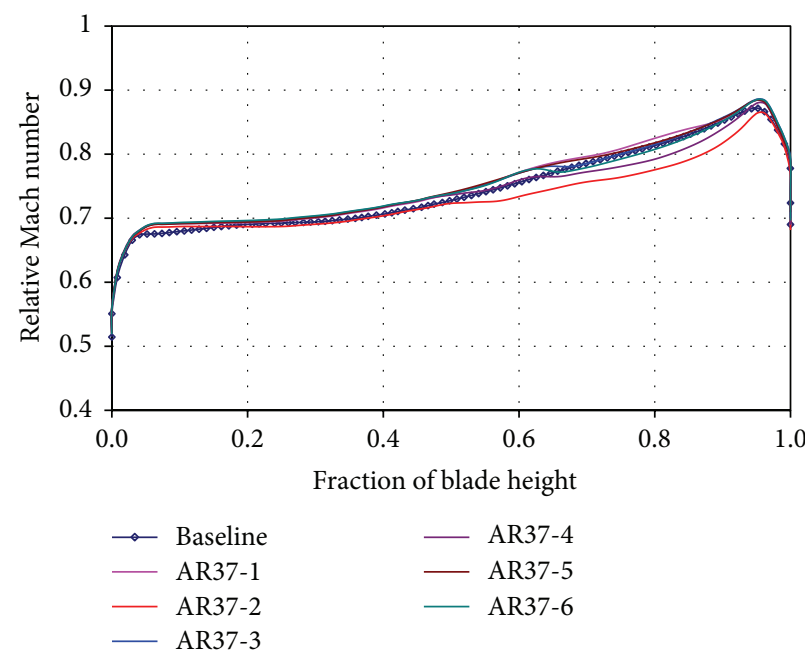

(a) Design mass flow rate

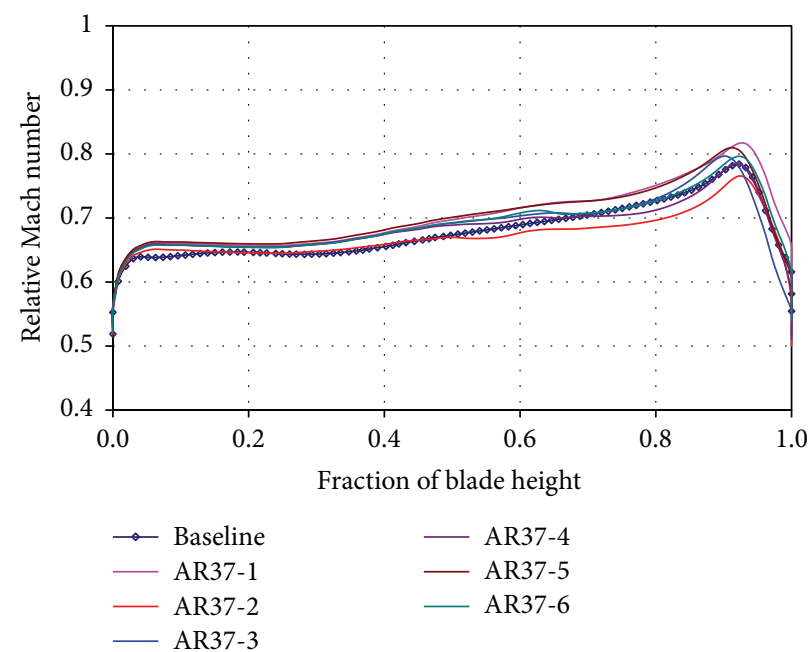

(b) Near-stall mass flow rate

FIGURE 15: Radial variation of relative Mach number at exit to rotor for different aspiration slot configurations (100\% design rotational speed).

The flow features of interest are observed in Figure 16(b) at $72.5 \%$ span location, which passes through the middle of the aspirated slot height. The natural aspiration or crossing of passage fluid from pressure surface to suction surface through the slot is clearly seen. Referring to Figure 16(b), the low momentum boundary layer fluid on the suction surface is energized by the aspiration flow. The flow accelerates on the blade surface, pushing the original, but energized, boundary layer fluid away from the suction surface. However, a new and thinner boundary layer develops on the suction surface downstream of the trailing end of the aspiration slot. This energization of boundary layer fluid results in lesser tendency for the flow to separate, and the stall margin improves. The natural aspiration pushes the passage shock further upstream from the blade leading edge. Within the passage, the shock impinging on the suction surface of the adjacent blade becomes inclined under the influence of natural aspiration as compared to the normal one without aspiration. Referring to Figure 16(c), the effect of aspiration is felt at $50 \%$ span also, a spanwise location just below the lower spanwise end of the aspiration slot. The original boundary layer is energized with lesser tendency for flow separation.

Figure 17 shows comparison of the isentropic relative Mach number distribution on the blade surface at $72.5 \%$ blade span for baseline and aspirated blade AR37-2 at operating points corresponding to near-stall mass flow rate. The changes in the Mach number variation on both surfaces brought about by the presence of the aspiration are clearly seen. The dip in the Mach number on the pressure surface at $\sim 55 \%$ span is due to the aspiration flow entering the slot. Similarly, the jump in the Mach number on the suction surface at $\sim 62 \%$ span is due to the flow ejecting out through the aspiration slot at high velocity.

\section{Structural Analyses of Baseline and Aspirated Rotor Blades}

An obvious objection to incorporation of aspiration slot in a rotor blade would be that it may result in weakening the blade structurally. Hence, the aspirated blade was subjected to structural analysis using ANSYS SPARSE solver. The material chosen was Maraging Steel 200 with typical yield strength of $1379 \mathrm{MPa}$. One of the larger slit geometries (AR37-2) was selected for structural analysis to simulate the worst case scenario. A detailed account of the entire structural analysis is given by Jain [13].

The distributions of von Mises stresses on the pressure and suction surfaces of the baseline and aspirated rotor blade are compared in Figure 18. Local high stresses are observed at the lower end of the aspiration slot. But, even with a higher stress concentration on the aspirated blade, the magnitude of stresses is less compared to that of the baseline blade. Figure 19 shows blown-up views of the rotor blades of Figure 18, giving the distribution of von Mises stresses in the hub region. The peak stress occurs at the leading end near the root of the blade, and its magnitude is reduced for the blade with aspiration slot. The aspiration slot tends to reduce the blade mass resulting in lower centrifugal force at a higher radius, thus resulting in lower peak stress at the root compared to the baseline rotor blade. The peak stresses in both baseline and aspirated rotors are much lower than the yield stress for the material. Hence, the rotor with aspiration slot does not pose any structural integrity problem.

Another important aspect of structural analysis is the estimation of blade frequencies and flutter characteristics that will be surely affected by the introduction of the aspiration slot. It may be noted that NASA rotor 37 has low aspect ratio blades and the effect of slot on blade frequencies will not be as serious as in high aspect ratio blading. This paper has not addressed the issues of blade vibration and flutter because the main focus of the investigations was on the aerodynamic effect of natural aspiration.

\section{Conclusions}

A novel concept of enhancing the stall margin of a transonic axial compressor (NASA rotor 37) by natural aspiration 

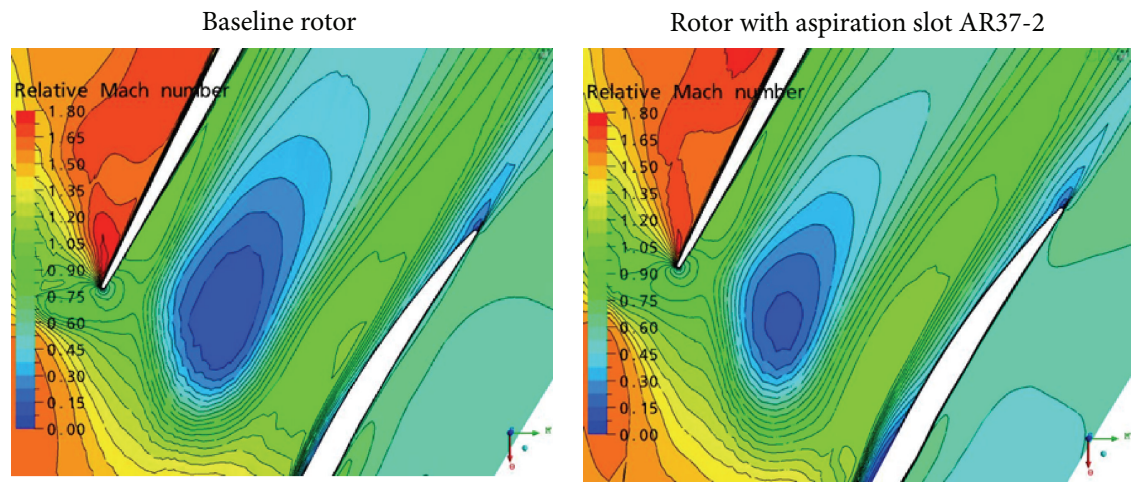

(a) $95 \%$ blade span from hub
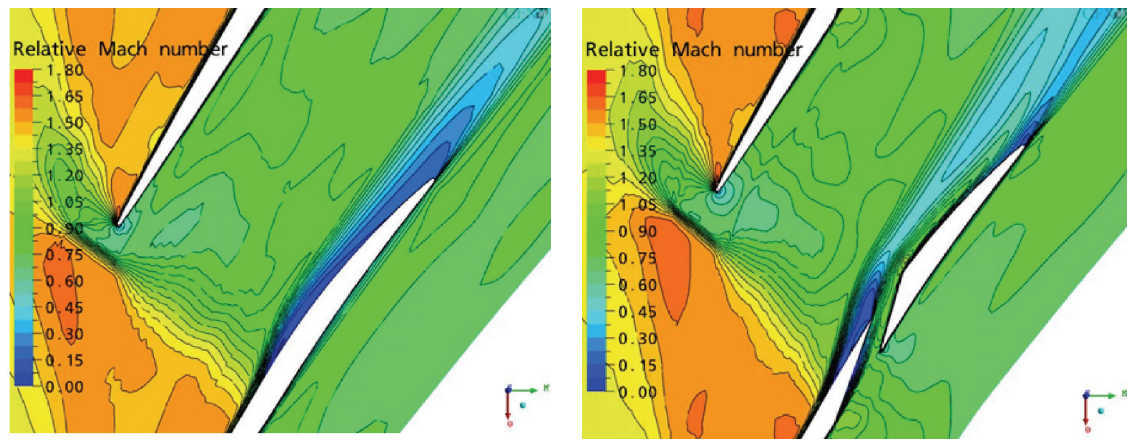

(b) $72.5 \%$ blade span from hub
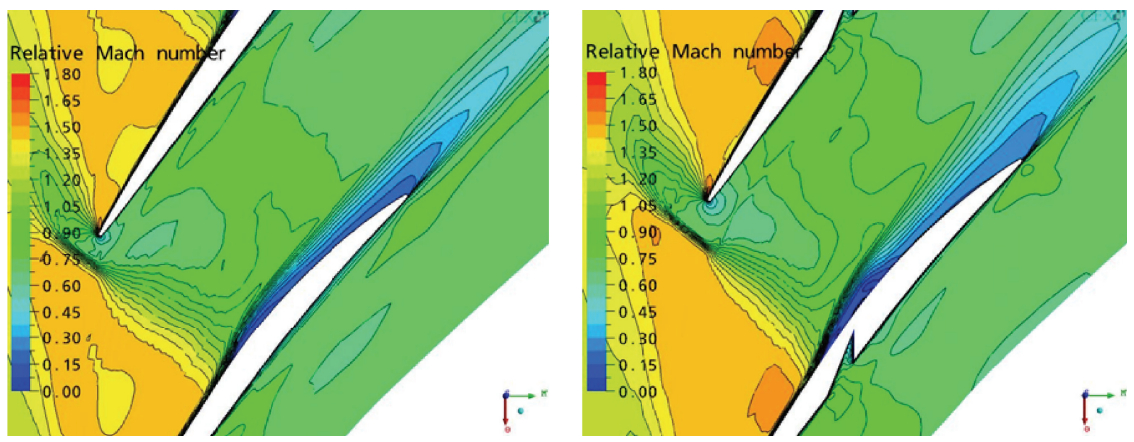

(c) $50 \%$ blade span from hub

FIGURE 16: Mach number distribution in the rotor blade passage without and with aspiration (AR37-2 slot) at three spanwise locations from hub (100\% design rotational speed, near-stall mass flow rate).

through a partial span slot in the rotor blade is presented. Six configurations of aspirated rotor with different aspiration slot geometries were examined. CFD simulations were performed on both baseline and aspirated rotors at design rotor speed. The results are presented and compared with respect to overall compressor performance and flow development through the blade passages. The following main conclusions are drawn from the present investigations:

(i) All the six aspirated slot configurations show a tendency for improvement in stall margin, accompanied by slight lowering of peak total pressure ratio and peak adiabatic efficiency of the compressor.

(ii) A maximum gain in stall margin of $\sim 3.2 \%$ is observed with the aspirated slot geometry, AR37-2, having a spanwise length of $28 \mathrm{~mm}$ and a width of $7 \mathrm{~mm}$ on the pressure surface and a width of $4 \mathrm{~mm}$ on the suction surface, and located at near mid-chord region of the blade.

(iii) However, the AR37-2 slot configuration produces a decrease in peak rotor pressure ratio by $1.42 \%$ and a decrease in peak adiabatic efficiency by $~ 2 \%$ compared to the baseline rotor.

(iv) The natural aspiration from pressure to suction surface is able to energize the suction surface boundary layer on the rotor blade with substantial reduction in the extent of low momentum fluid downstream of the point of injection. 


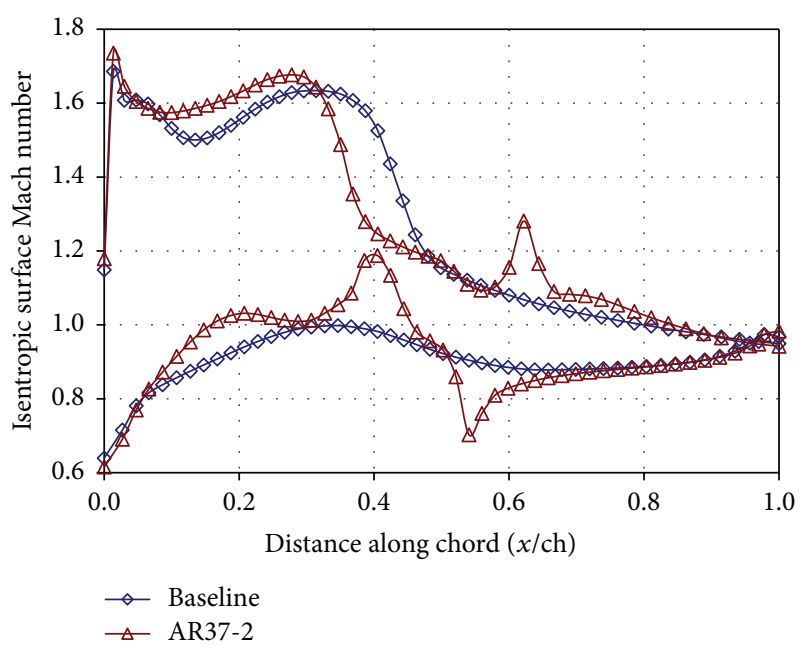

FIGURE 17: Isentropic Mach number variation on the blade surface with no aspiration and with AR37-2 aspiration slot at a radial location $72.5 \%$ span from hub (100\% design rotational speed).
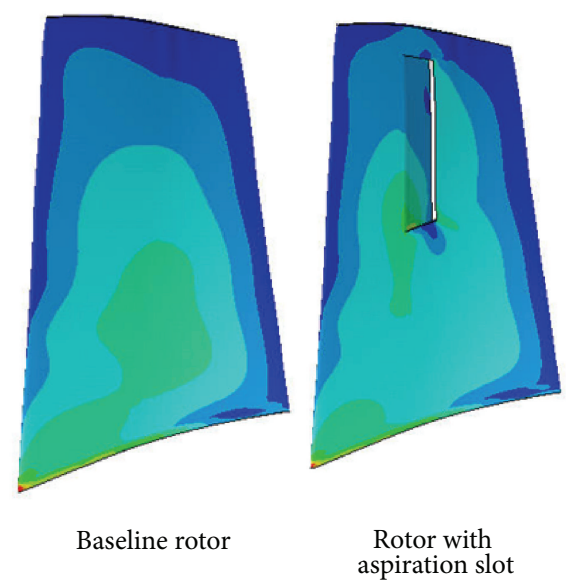

von Mises stress $(\mathrm{MPa})$

Baseline rotor

(a) Pressure surface
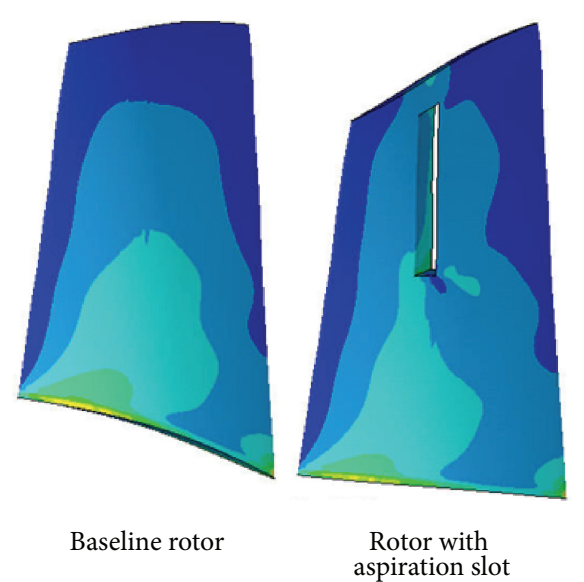

von Mises stress $(\mathrm{MPa})$

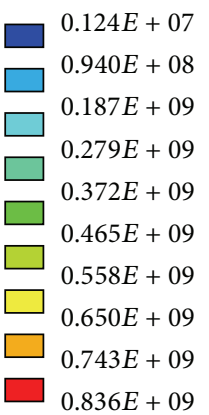

Baseline rotor

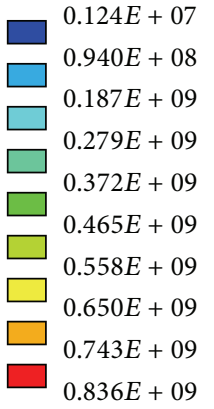

$0.836 E+09$

(b) Suction surface

FIGURE 18: von Mises stress distribution on pressure and suction surfaces of the rotor blade without and with aspiration (AR37-2) at design mass flow rate.

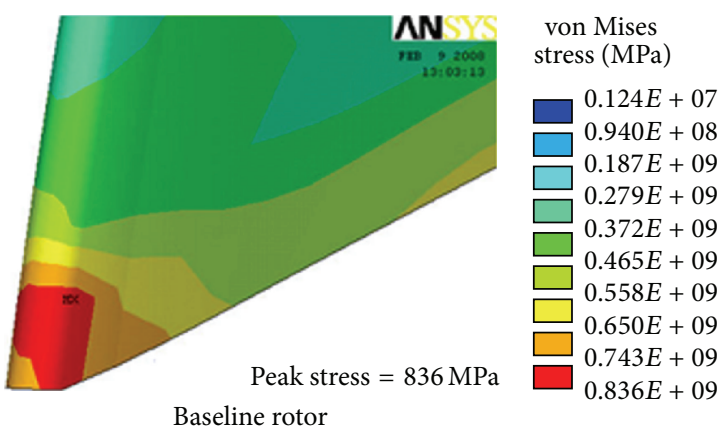

(a)

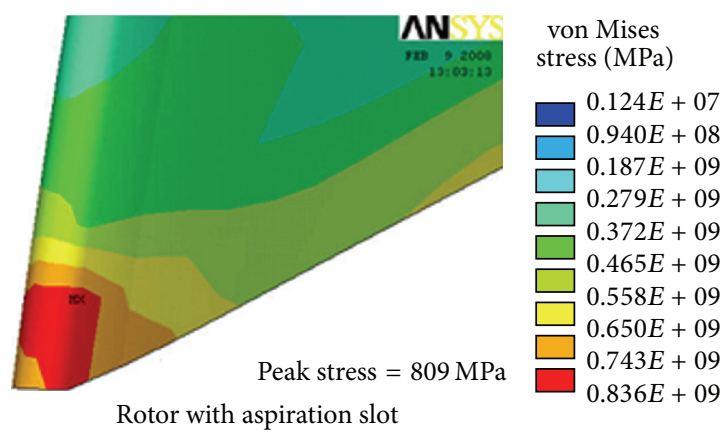

(b)

FIGURE 19: von Mises stress distribution in the hub region of the rotor blade without and with aspiration (AR37-2) at design mass flow rate showing the location of peak stresses.

(v) The selection of chordwise location and inclination of the slot with respect to the suction surface is influenced by the passage shock impingement location on the suction surface.

(vi) The aspiration slot does not appreciably alter the stress distribution and peak stress in the blade compared to the baseline solid blade.

\section{Nomenclature}

Ch: Blade chord

$k$ : Turbulence kinetic energy, $\mathrm{m}^{2} / \mathrm{s}^{2}$

$P_{0}$ : Total pressure, $\mathrm{Pa}$

$T_{0}$ : Total temperature, $\mathrm{K}$

$x$ : Distance along axial chord

$\varepsilon$ : Turbulence kinetic energy dissipation rate, $\mathrm{m}^{2} / \mathrm{s}^{3}$

AR: Aspirated rotor

LE: Leading end

PS: Pressure surface

PR: Pressure ratio

SS: Suction surface

TE: Trailing end.

\section{Conflict of Interests}

The authors declare that there is no conflict of interests regarding the publication of this paper. 


\section{Acknowledgment}

The authors are thankful to the authorities of M.S. Ramaiah University of Applied Sciences, Bangalore, India, for granting permission to publish this research work.

\section{References}

[1] I. A. Johnson and R. O. Bullock, "Aerodynamic design of axial flow compressors," NASA SP-36, 1965.

[2] B. J. Schuler, J. L. Kerrebrock, and A. Merchant, "Experimental investigation of a transonic aspirated compressor," Journal of Turbomachinery, vol. 127, no. 2, pp. 340-348, 2005.

[3] A. Merchant and J. L. Kerrebrock, "Experimental investigation of a high pressure ratio aspirated fan stage," Paper ASME GT2004-53679 [NASA TM-2004-213080], 2004.

[4] J. Kerrebrock, "Research and development on aspirated compressors," AFOSR/NA Technical Report AFRL-SR-AR-TR-040285, 2003.

[5] G. A. C. Falla, Numerical investigation of the flow in tandem compressor cascades [Research thesis], Vienna University of Technology, Institute of Thermal Power Plants, Vienna, Austria, 2004.

[6] A. Merchant, "Aerodynamic design and performance of aspirated airfoils," Journal of Turbomachinery, vol. 125, no. 1, pp. 141148, 2003.

[7] J. H. Freedman, "Design of a multi-spool, high-speed, counterrotating, aspirated compressor," AFIT/CIA 20001120094, 2000.

[8] T. Q. Dang, M. V. Rooij, and L. M. Larosiliere, "Design of aspirated compressor blades using three-dimensional inverse method," NASA Technical Memorandum TM-2003-212212; ARL-TR-2957; GT-2003-38492, 2003.

[9] J. L. Kerrebrock, Control of flow in compressors by suction/mechanical design of an experimental aspirated compressor [Research Thesis], Vienna University of Technology, Institute of Thermal Power Plants, Vienna, Austria, 1997.

[10] S. Guo, H. W. Lu, J. Liu, and C. J. Wu, "The effects of cavity geometry on an aspirated compressor cascade," Journal of Theoretical and Applied Mechanics, vol. 52, no. 1, pp. 117-128, 2014.

[11] Y. Liu, J. Sun, and L. Lu, "Corner separation control by boundary layer suction applied to a highly loaded axial compressor cascade," Energies, vol. 7, no. 12, pp. 7994-8007, 2014.

[12] L. Reid and R. D. Moore, "Design and overall performance of four highly loaded, high speed inlet stages for an advanced high pressure ratio core compressor," NASA Technical Paper TP-1337, NASA, 1978.

[13] V. K. Jain, Numerical investigations on aspirated transonic axial compressor rotor [M.S. thesis], Ramaiah School of Advanced Studies, Bangalore, India, 2008.

[14] J. D. Denton, "Lessons from rotor 37," Journal of Thermal Science, vol. 6, no. 1, pp. 1-13, 1997.

[15] K. L. Suder, Blockage Development in a Transonic, Axial Compressor Rotor, ASME Turbo Expo, Orlando, Fla, USA, 1997. 

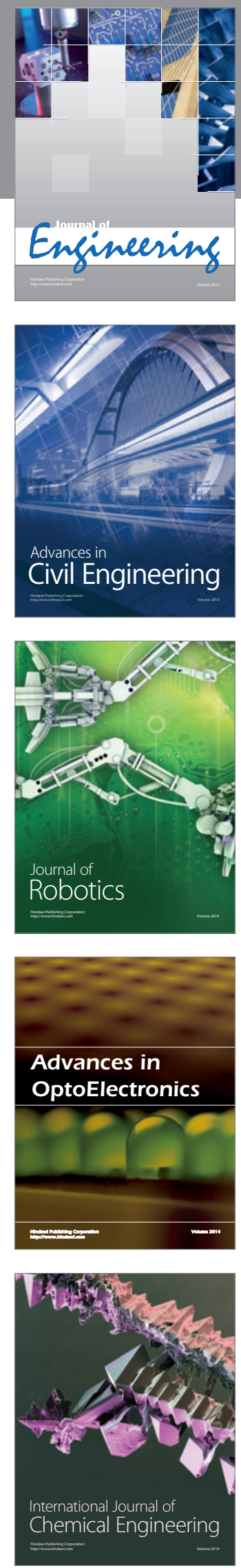

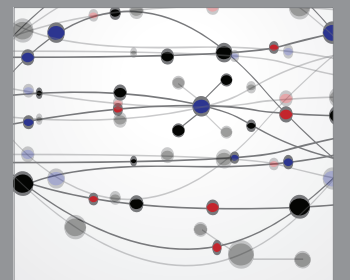

The Scientific World Journal
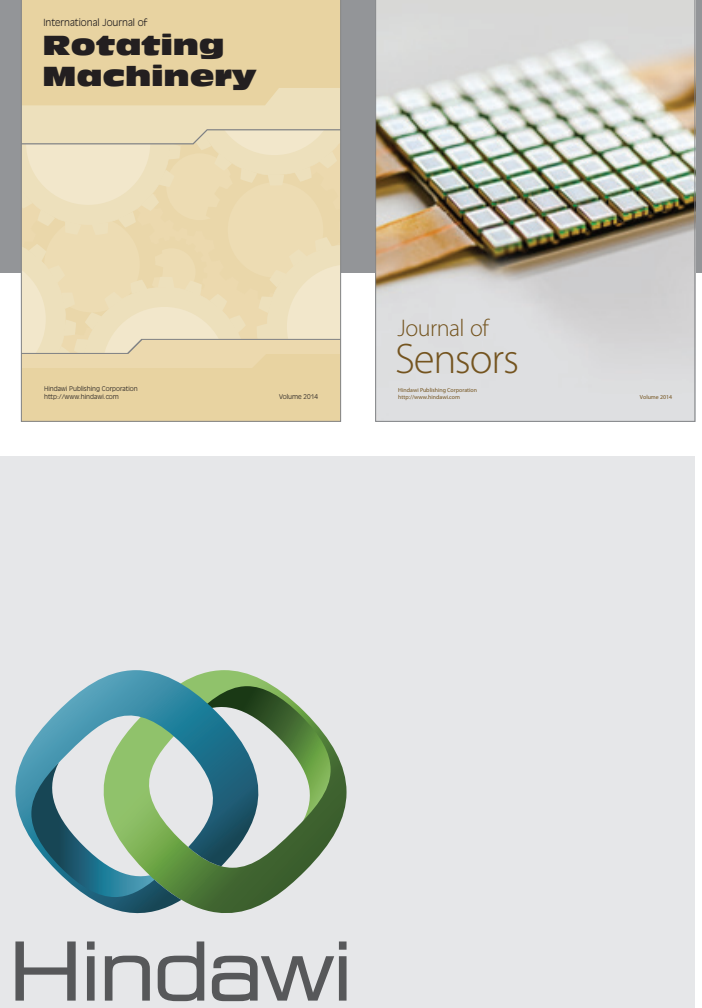

Submit your manuscripts at http://www.hindawi.com
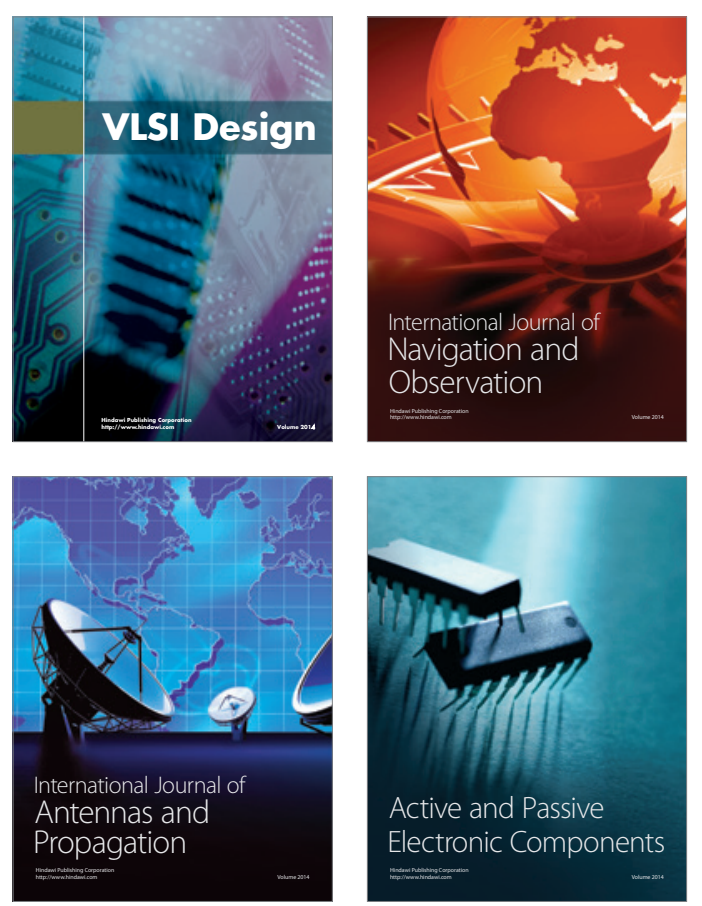
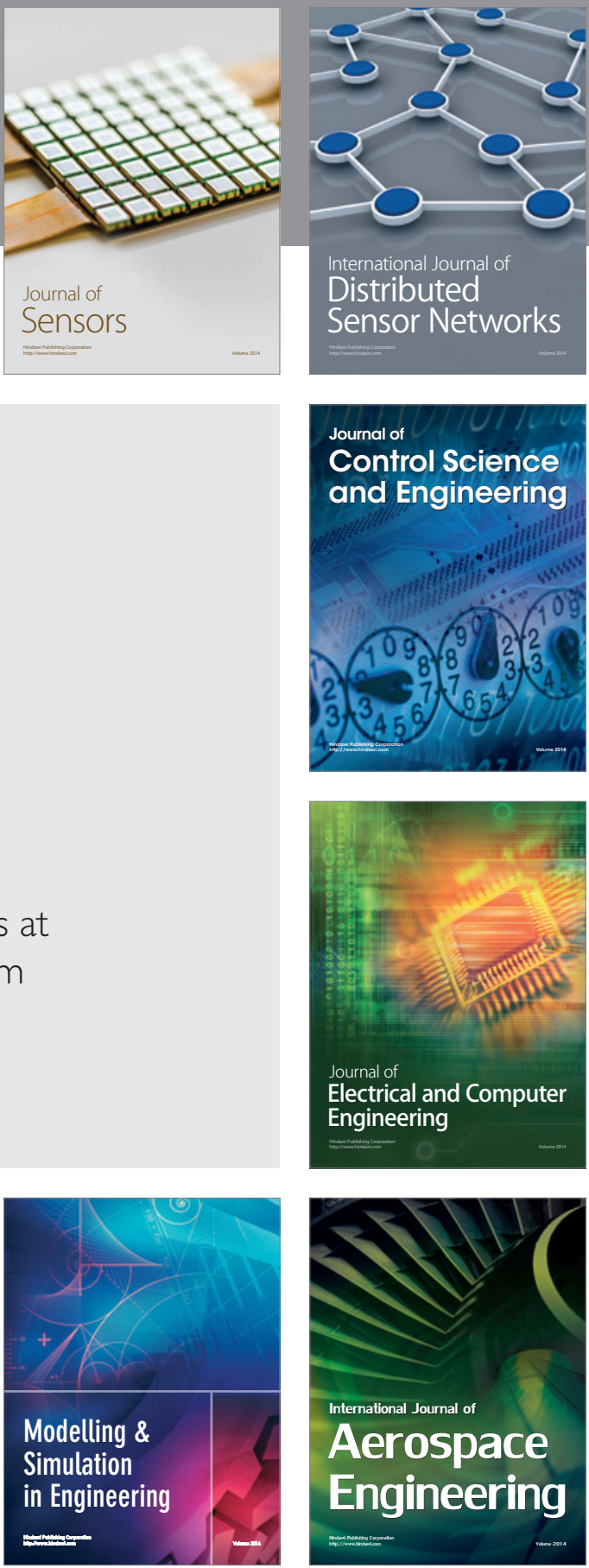

Journal of

Control Science

and Engineering
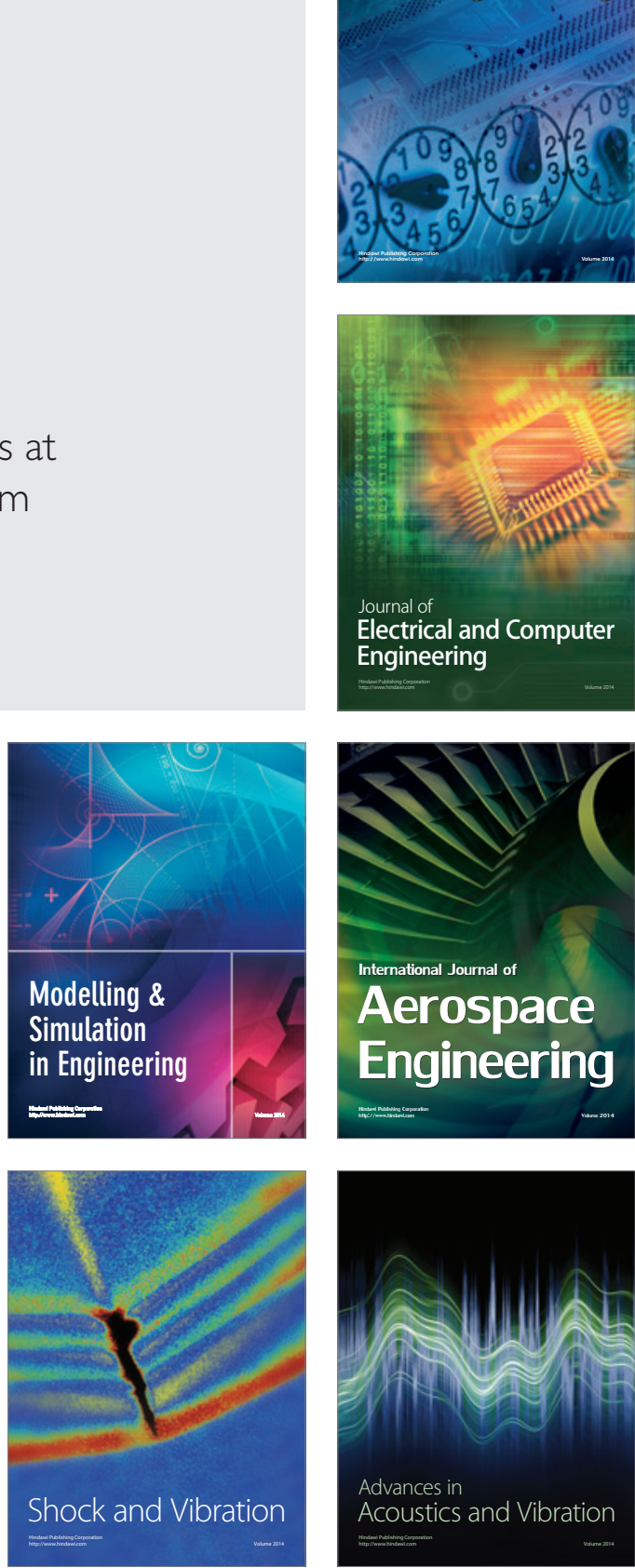